\title{
Encapsulation of Bitter gourd (Momordica charantia L.) Extract by Spray Drying Technique
}

\author{
Navveen Raj and B Priya* \\ Department of Food process engineering, \\ School of Bioengineering, SRM University, Chennai, Tamil Nadu, India-603 203. \\ http://dx.doi.org/10.13005/bbra/2151
}

(Received: 27 March 2016; accepted: 10 May 2016)

Bitter gourd (Momordica charantia L.) possesses anti-fungal, anti-bacterial, anti-parasitic, anti-viral, anti-fertility, anti-tumorous, hypoglycemic properties etc., The objective of the present work is to encapsulate homogenized bitter gourd extract using spray drying technique. The homogenized bitter gourd extract is obtained by high pressure homogenizer at 300 psi and it is spray dried using wall material such as maltodextrin and gum acacia in varied core to wall ratios $(1: 2 \& 1: 3)$ and different drying inlet air temperatures $140^{\circ} \mathrm{C}$ and $160^{\circ} \mathrm{C}$. The physico-chemical analysis like phyto-chemical screening, colour, bulk density, tap density, water activity, water solubility were determined for the encapsulated bitter gourd extract powder. The optimized encapsulated bitter gourd extract powder was core to wall ratio 1:3 and drying inlet air temperature $160^{\circ} \mathrm{C}$.

Keywords: High pressure homogenization, physico-chemical properties, water activity, water solubility, core to wall ratio.

Bitter gourd (Momordica charantia L.) is a popular vegetable in Southeast Asia. It is a member of the 'Cucurbitaceae' family. Depending on location, bitter gourd is also known as bitter melon, karalla. The immature fruits and tender vine tips are used in a variety of culinary preparations. The fruit of M. charantia is commonly known for its remarkable bitter taste, so the fruits are soaked in salt water to remove some of their bitterness and then boiled, fried or pickled. Bitter gourd contains phyto-nutrients like charantin, linoleic acid, momordicins, oleic acid, oxalic acid, trypsin inhibitors, lycopene, â-sitosterol-d-glucoside and pipecoloc acid ${ }^{1}$. So medicinal value of bitter gourd

\footnotetext{
* To whom all correspondence should be addressed. Tel.: +9198944 36749

E-mail: priya.balasubramani@gmail.com
}

accounts for anti-diabetic, anti-inflammatory, anticancer, anti-tumor, anti-microbial and has cholesterol lowering effect. Many value added products of bitter gourd are available like tablets, tea, syrup and powder for its tremendous medicinal values.

High pressure homogenization is a technology in which fluid is pumped through a narrow gap valve using high pressure intensifiers, which increases velocity resulting in depressurization with consequent cavitation and the particles, cells and macromolecules suspended in the fluid will get reduced particle size due to high mechanical stress ${ }^{2,3}$.

Microencapsulation is described as a technique wherein a bioactive compound is encapsulated by a biopolymer, thereby protecting it from oxygen, water or other conditions to improve its stability ${ }^{4}$. This method is also used to change 
liquid solutions to powders, which are easier to handle and which enhances the shelf life of the product.

Drying by atomization, or spray drying, refers to the removal of moisture from fluid material (solution, dispersion or paste) by breaking it into small droplets in the presence of hot air to obtain a dry powder. In the spray-drying process, the liquid feed is pumped into the drying chamber through an atomizing system ${ }^{5,6}$. It results in powders with good quality, low water activity, easier handling and storage and also protects the active material against undesirable reactions. Both wall material selection and emulsion properties can affect the process efficiency and the microencapsulated product stability. Microencapsulation using this technique has been around for decades in diverse industrial processes to obtain dehydrated materials in the form of fine powders, and it is the most used method in the food industry ${ }^{7,8}$.

\section{MATERIALSAND METHODS}

\section{Chemicals}

Chloroform, sulphuric acid, potassium permanganate, Mayer's reagent, sodium hydroxide, Benedicts's reagent, ferric chloride solution, ethanol, distilled water, maltodextrin and gum acacia.

\section{Collection of vegetable}

Bitter gourd (M. charantia L.) was purchased from local markets of Chennai, India. The vegetable was brought to the laboratory and rinsed with water, surface sterilized and refrigerated for further processing.

\section{Preparation of Bitter gourd extract}

The process started with selection of bitter gourd which is visually green colour and absence of yellow colour, hardness and overall condition of bitter gourd (no bruise). The vegetable was washed, peeled and seeds are removed, sliced into small pieces. The bitter gourd pieces were subjected to grind using a blender along with addition of an appropriate amount of distilled water to make bitter gourd extract. The prepared bitter gourd extract was subjected to High pressure homogenizer (Model - Panda 2K) at pressure 300psi.

\section{Wall material preparation}

Different concentrations of wall materials were prepared, $50 \%$ maltodextrin and $20 \%$ gum acacia in $100 \mathrm{ml}$ distilled water separately.

\section{Core to wall ratio}

The fifty grams of homogenized bitter gourd extract was mixed with $50 \mathrm{~g}$ of $50 \%$ maltodextrin concentration and $50 \mathrm{~g}$ of $20 \%$ Gum acacia concentration to prepare core to wall ratio of $1: 2$. Similarly core to wall ratio of $1: 3$ were prepared.

\section{Preparation of feed emulsion for Spray drying}

The feed emulsions were prepared by blending the desired core and wall material in shear homogenizer (Indofrench Industries Engineers, Mumbai, and Model type SPM-9) for 5 min. Tween 80 was added to aid emulsification process ${ }^{9}$.

\section{Spray dryer}

Tall type Spray dryer was used for spray drying process with two different drying inlet air temperatures, $140^{\circ} \mathrm{C}$ and $160^{\circ} \mathrm{C}$ and outlet air temperature was $95^{\circ} \mathrm{C}$. The pressure of the compressed air flow of the spray was adjusted to $350 \mathrm{kPa}^{10}$.

\section{Phytochemical screening}

The encapsulated bitter gourd extract powder is reconstituted using water and $2 \mathrm{ml}$ was taken separately for preliminary phytochemical examination ${ }^{11}$ as follows:

\section{Test for Alkaloids}

Dilute hydrochloric acid was added to the samples and filtered. Mayer's reagent was added to the filtrate resulting in alkaloid precipitates, indicating the presence of alkaloids in the samples.

\section{Test for Reducing Sugar}

Dilute sodium hydroxide solution and Benedict's solution was added to the samples, resulting in brick-red precipitate, indicating the presence of a reducing sugar.

\section{Test for Tannins}

Few drops of ferric chloride solution was added to test sample, a deep blue color was produced indicating the presence of tannins.

\section{Test for Charantin}

Decolourisation takes place when samples are added to dilute potassium permanganate

\section{Test for terpenoids}

To the sample, $2 \mathrm{ml}$ of chloroform is added and $3 \mathrm{ml}$ of con. $\mathrm{H}_{2} \mathrm{SO}_{4}$ was then added to form a layer. A reddish brown precipitate at the interface formed indicated the presence of terpenoids. 


\section{Test for flavonoids}

To the samples few drops of $20 \%$ sodium hydroxide solution is added resulting in yellow colour which on addition of sulphuric acid changes it into colorless shows the presence of flavonoids.

\section{Test for carotenoids}

To the samples, $10 \mathrm{ml}$ of chloroform is added in a test tube and mixed thoroughly. The resulting mixture was filtered and $85 \%$ sulphuric acid was added. A blue colour at the interface showed the presence of carotenoids.

\section{Colour}

The Colour determination was carried out using a Hunter lab Color Quest (Model, XE 3399) with a white tile as standard and all samples were analyzed. The Hunter ' $L$ ', $a *$ and $b *$ values were measured, where ' $L$ ' indicates lightness, $a^{*}$ indicates redness (green to red) and $\mathrm{b}^{*}$ indicates yellowness (blue to yellow). Triplicate readings were recorded for all treatments.

\section{Density}

The bulk density measurement was done by dropping the powder in a container of defined size such as a measuring cylinder $10 \mathrm{ml}$ and the volume is noted. The tap density measurement was done by measuring the volume in the cylinder after mechanically tapped to get the constant volume 12

Bulk density = Powder mass/volume of powder Tap density = Mass of the powder / Final tapped volume

\section{Water activity}

Water activity was determined by

Novasina Lab Swift water activity meter.

\section{Water Solubility}

Encapsulated bitter gourd extract powder of $1 \mathrm{~g}$ was mixed with $10 \mathrm{ml}$ distilled water in a centrifuge tube. The centrifuge tube is heated to 80ÚC for 30 minutes with continuous shaking. The tube is removed from the bath, wiped dry, cooled to room temperature and centrifuged for 15 minutes at $2200 \mathrm{rpm}$. The supernatant is evaporated, and the residue is weighed to determine the solubility. Solubility is determined using the formula:

Solubility $\%=$ (weight of dry sample in supernatant/weight of original sample) X100

\section{RESULTSAND DISCUSSION}

\section{Phytochemical Screening}

The results in Table 1 show the phytochemical screening of encapsulated bitter

Table 1. Phytochemical Screening Of Spray Dried Bitter Gourd Powder

\begin{tabular}{|c|c|c|c|c|c|c|}
\hline \multirow{3}{*}{$\begin{array}{l}\text { Quality } \\
\text { parameter }\end{array}$} & \multirow{3}{*}{\multicolumn{2}{|c|}{ Observation }} & \multicolumn{4}{|c|}{ Encapsulated bitter gourd extract powder } \\
\hline & & & \multicolumn{2}{|c|}{$1: 2$} & \multicolumn{2}{|c|}{$1: 3$} \\
\hline & & & $140^{\circ} \mathrm{C}$ & $160^{\circ} \mathrm{C}$ & $140^{\circ} \mathrm{C}$ & $160^{\circ} \mathrm{C}$ \\
\hline Terpenoids & Reddish br & n precipitate & + & + & + & + \\
\hline Tannins & Deep 1 & e colour & + & + & + & + \\
\hline Charantin & Decol & risation & + & + & + & + \\
\hline Flavonoids & Colourl & s solution & + & - & + & + \\
\hline Carotenoids & Blue col & r interface & + & + & + & + \\
\hline Alkaloids & Alkaloi & recipitate & + & + & + & + \\
\hline Reducing sugar & Brick re & precipitate & + & - & + & + \\
\hline \multicolumn{7}{|c|}{$\begin{array}{l}\text { "+” indicates the presence of phytonutrient, } \\
\text { "-" indicates the absence of phytonutrient }\end{array}$} \\
\hline \multicolumn{7}{|c|}{ Table 2. Colour Values Of Spray Dried Bitter Gourd Powder } \\
\hline \multirow{2}{*}{\multicolumn{2}{|c|}{ Standard (white tile) }} & 'L' & \multirow{2}{*}{\multicolumn{2}{|c|}{$\begin{array}{c}a^{*} \\
0.83\end{array}$}} & \multicolumn{2}{|l|}{$\mathrm{b}^{*}$} \\
\hline & & 94.05 & & & \multicolumn{2}{|l|}{1.57} \\
\hline \multirow[t]{2}{*}{$1: 2$} & $140^{\circ} \mathrm{C}$ & $86.69 \pm 0.08$ & \multicolumn{2}{|c|}{$1.43 \pm 0.06$} & \multicolumn{2}{|c|}{$9.82 \pm 0.04$} \\
\hline & $160^{\circ} \mathrm{C}$ & $84.89 \pm 0.04$ & \multicolumn{2}{|c|}{$1.37 \pm 0.03$} & \multicolumn{2}{|c|}{$9.15 \pm 0.03$} \\
\hline \multirow[t]{2}{*}{$1: 3$} & $140^{\circ} \mathrm{C}$ & $87.65 \pm 0.08$ & \multicolumn{2}{|c|}{$1.26 \pm 0.02$} & \multicolumn{2}{|c|}{$8.28 \pm 0.07$} \\
\hline & $160^{\circ} \mathrm{C}$ & $87.15 \pm 0.05$ & \multicolumn{2}{|c|}{$1.21 \pm 0.04$} & \multicolumn{2}{|c|}{$8.26 \pm 0.05$} \\
\hline
\end{tabular}


Table 3. Bulk And Tap Density Values For Encapsulated Bitter Gourd Extract Powder

\begin{tabular}{llcc}
\hline \multirow{2}{*}{$\begin{array}{c}\text { Encapsulated bitter } \\
\text { gourd extract powder }\end{array}$} & Bulk density $\left(\mathrm{kg} / \mathrm{m}^{3}\right)$ & Tap density $\left(\mathrm{kg} / \mathrm{m}^{3}\right)$ \\
\hline \multirow{2}{*}{$1: 2$} & $140^{\circ} \mathrm{C}$ & $0.316 \pm 0.008$ & $0.413 \pm 0.003$ \\
& $160^{\circ} \mathrm{C}$ & $0.307 \pm 0.001$ & $0.405 \pm 0.000$ \\
& $140{ }^{\circ} \mathrm{C}$ & $0.331 \pm 0.004$ & $0.442 \pm 0.006$ \\
& $160^{\circ} \mathrm{C}$ & $0.311 \pm 0.005$ & $0.417 \pm 0.007$ \\
\hline
\end{tabular}

Table 4. Water Activity Of Spray Dried Bitter Gourd Powder

\begin{tabular}{lll}
\hline $\begin{array}{l}\text { Encapsulated Bitter } \\
\text { Gourd extarct powder }\end{array}$ & Water activity $\left(\mathrm{a}_{\mathrm{w}}\right)$ \\
\hline \multirow{2}{*}{$1: 2$} & $140^{\circ} \mathrm{C}$ & 0.34 \\
& $160^{\circ} \mathrm{C}$ & 0.31 \\
$1: 3$ & $140^{\circ} \mathrm{C}$ & 0.33 \\
& $160^{\circ} \mathrm{C}$ & 0.30 \\
\hline
\end{tabular}

gourd extract powder. The test indicated that the encapsulated bitter gourd extract powder showed the presence of phytonutrients but the core to wall ratio $1: 2$ at spray drying inlet air temperature $160^{\circ} \mathrm{C}$ lacks reducing sugar 1 and flavonoids as they may be because of high temperature and low core to wall ratio.

\section{Colour}

The results in Table 2 show the colour values for encapsulated bitter gourd extract powder which indicates that as spray drying inlet air temperature increases colour decreases and as core to wall ratio increases colour increases. This is because more wall material leads to high adherence of sample to wall material and maltodextrin concentration has impact on colour of the powder 13 .

\section{Density}

Table 3 shows the values obtained for the encapsulated bitter gourd extract powder. The bulk density decreased with the increase in the spray drying inlet air temperature ${ }^{14}$. Similarly, the increase in the inlet air temperature resulted in the decrease of tapped density ${ }^{15}$.

\section{Water activity}

Table 4 shows the water activity of the encapsulated bitter gourd extract powder. Water
Table 5. Water Solubility Of Spray Dried Bitter Gourd Powder

\begin{tabular}{lrl}
\hline \multicolumn{2}{l}{$\begin{array}{l}\text { Encapsulated Bitter } \\
\text { Gourd powder }\end{array}$} & Water solubility \\
\hline $1: 2$ & $140^{\circ} \mathrm{C}$ & 55.3 \\
& $160^{\circ} \mathrm{C}$ & 54.2 \\
$1: 3$ & $140^{\circ} \mathrm{C}$ & 68.3 \\
& $160^{\circ} \mathrm{C}$ & 70.1 \\
\hline
\end{tabular}

activity has a slight difference and the values were ranging from 0.30 to 0.35 which indicates that the powder is microbiologically safe ${ }^{16}$.

\section{Water Solubility}

Solubility is important for powder products in order to reconstitute the product. Mostly starch derivatives have high solubility. Maltodextrin, a derivative of corn starch is used as wall material so as the concentration increases solubility of the powder increases ${ }^{17}$. Table 5 shows the water solubility of spray dried bitter gourd extract powder.

\section{Optimization}

The process parameters were optimized by giving the desirability to all responses and the optimized parameter were core to wall ratio 1:3 at drying inlet air temperature $160^{\circ} \mathrm{C}$.

\section{CONCLUSION}

The present work evaluated the quality of the encapsulated bitter gourd extract powder by determining its colour, presence of phytonutrients, water activity, bulk density, tap density and water solubility. The optimized encapsulated bitter gourd extract powder can be incorporated in food. 


\section{REFERENCES}

1. Dhalla, N.S., Gupta, K.C., Sastry, M.S., Malhotra, C.L. Chemical composition of the fruit of Momordica charantia L. Indian Journal of Pharmacology., 1961; 23: 128-131

2. Navveen Raj, M., Priya, B., Preetha, R. Optimization of extraction of bitter gourd (Momordica charantia L.) extract. Indian Journal of Science., 2015; 22(76): 75-82

3. Pinho, C. R. G., Franchi, M. A., Augusto, P. E. D., \& Cristianini, M. Milk flow evaluation during high pressure homogenization (HPH) using computational fluid dynamics (CFD). Brazilian Journal of Food Technology., 2011; 14(3): 232-240

4. Desai, K. G. H., \& Park, H. J. Recent development in microencapsulation of foods ingredients. Drying Technology., 2005; 23: 13611394

5. Al-asheh, S., Jumah, R., Banat, F., Hammad, S. The use of experimental factorial design for analysing the effect of spray dryer operating variables on the production of tomato powder. Food Bio product. Process., 2003; 81 (2): 8188

6. Ré, M.I. Microencapsulation by spray drying. Dry Technology., 1998; 16: 1195-1236

7. Jackson, L.S., Lee, K. Microencapsulation Food Industry. Lebensmittel-Wissenschaft \& Technology., 1991; 24 (4): 289-297

8. Jafari, S.M., Assadpoor, E., He, Y., Bhandari, B. Encapsulation efficiency of food flavors and oils during spray drying. Dry Technology., 2008; 26: 816-835

9. Priya, Balasubramani, Viswanathan,R., and Vairamani,M., Response Surface Optimisation of Process Variables for Microencapsulation of
Garlic (Allium sativum L.) Oleoresin by Spray Drying. Biosystems Engineering, 2013; 114(3): 205-213.

10. Priya, Balasubramani, Palaniswamy, P.T., Visvanathan, R., Thirupathi, V., and Subbarayan, A., and Prakash Maran. J., Microencapsulation of Garlic Oleoresin using Maltodextrin as Wall Material by Spray Drying Technology. International Journal of Biological Macromolecules. 2015; 72: 210-217.

11. Yadav, R.N.S., and Munin Agarwala. Phytochemical analysis of some medicinal plants. Journal of Phytology, 2011; 3(12): 10-14

12. Ng Lay Tze, Chong Pik Han., Yus Aniza Yusof., Chin Nyuk Ling., Rosnita A. Talib., Farah Saleena Taip., Mohammad Gulzarul Aziz. Physicochemical and nutritional properties of spray-dried pitaya fruit powder as natural colorant. Food Science Biotechnology., 2012; 21(3): 675-682

13. Quek, S.Y., Chok, N.K. and Sherlund, P. The physicochemical properties of spray-dried watermelon powders. Chemical Engineering and Processing., 2007; 46(5): 386-392

14. Cevat Aydýna., Musa Özcan. Some physicomechanic properties of terebinth (Pistacia terebinthus L.) fruits., 2002; 53: 97-101

15. Cai, Y.Z., Corke, H. Production and properties of spray-dried Amaranthus betacyanin pigments. Journal of Food Science., 2000; 65: 1248-1255

16. Porrarud, S., Pranee, A., Microencapsulation of Zn- chlorophyll pigment from pandan leaf by spray drying and its characteristics. International food research journal, 2007; 17: 1031-1042

17. Ersus, S., Yurdagel, U. Microencapsulation of Anthocyanin Pigments of Black Carrot (Daucus carota L.) by Spray Drier. Journal of Food Engineering., 2007; 80: 805-812 